\title{
Regulation of sclerostin in
}

\section{glucocorticoid-induced osteoporosis (GIO) in mice and humans}

\author{
Sylvia Thiele ${ }^{1,2}$, Anke Hannemann ${ }^{3}$, Maria Winzer ${ }^{1,2}$, Ulrike Baschant $^{1,2}$, Heike Weidner ${ }^{1,2}$, Matthias Nauck ${ }^{3}$, \\ Rajesh V Thakker ${ }^{4}$, Martin Bornhäuser ${ }^{5,6}$, Lorenz C Hofbauer ${ }^{1,2,6}$ and Martina Rauner ${ }^{1,2}$ \\ ${ }^{1}$ Department of Medicine III, Technische Universität Dresden, Dresden, Germany \\ ${ }^{2}$ Center for Healthy Aging, Technische Universität Dresden, Dresden, Germany \\ ${ }^{3}$ Institute of Clinical Chemistry and Laboratory Medicine, University Medicine Greifswald, Greifswald, Germany \\ ${ }^{4}$ Academic Endocrine Unit, Radcliffe Department of Medicine University of Oxford, Oxford Centre for Diabetes, Endocrinology, and Metabolism, Churchill \\ Hospital, Oxford, UK \\ ${ }^{5}$ Department of Medicine I, Technische Universität Dresden, Dresden, Germany \\ ${ }^{6}$ DFG Research Center and Cluster of Excellence for Regenerative Therapies, Technical University, Dresden, Germany
}

\begin{abstract}
Glucocorticoids (GC) are used for the treatment of inflammatory diseases, including various forms of arthritis. However, their use is limited, amongst others, by adverse effects on bone. The Wnt and bone formation inhibitor sclerostin was recently implicated in the pathogenesis of GC-induced osteoporosis. However, data are ambiguous. The aim of this study was to assess the regulation of sclerostin by GC using several mouse models with high GC levels and two independent cohorts of patients treated with GC. Male 24-week-old C57BL/6 and 18-week-old DBA/1 mice exposed to GC and 12-week-old mice with endogenous hypercortisolism displayed reduced bone formation as indicated by reduced levels of P1NP and increased serum sclerostin levels. The expression of sclerostin in femoral bone tissue and GC-treated bone marrow stromal cells, however, was not consistently altered. In contrast, GC dose- and time-dependently suppressed sclerostin at mRNA and protein levels in human mesenchymal stromal cells, and this effect was GC receptor dependent. In line with the human cell culture data, patients with rheumatoid arthritis (RA, $n=101)$ and polymyalgia rheumatica (PMR, $n=21)$ who were exposed to GC had lower serum levels of sclerostin than healthy age- and sex-matched controls $(-40 \%, P<0.01$ and $-26.5 \%, P<0.001$, respectively). In summary, sclerostin appears to be differentially regulated by GC in mice and humans as it is suppressed by GCs in humans but is not consistently altered in mice. Further studies are required to delineate the differences between $\mathrm{GC}$ regulation of sclerostin in mice and humans and assess whether sclerostin mediates GC-induced osteoporosis in humans.
\end{abstract}

\author{
Key Words \\ - sclerostin \\ - glucocorticoid-induced \\ osteoporosis \\ - bone remodeling \\ - bone marrow stromal cells \\ - glucocorticoid receptor
}

\section{Introduction}

Glucocorticoids (GCs) are effective drugs in the treatment of immune-mediated diseases, including rheumatoid arthritis or allergic diseases such as asthma. However, their administration is often accompanied by adverse effects on bone mass and strength, resulting in increased osteoporotic fracture probability (1). Chronic GC therapy leads to decreased bone mineral density, and up to 50\% of treated patients experience vertebral fractures (2). The complex pathogenesis of glucocorticoid-induced osteoporosis (GIO) involves many organ systems. At the skeletal level,

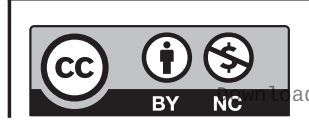

This work is licensed under a Creative Commons Attribution-NonCommercial 4.0 International License. ded from Bioscientifica.com at 04/26/2023 11:00:23AM 
GCs stimulate osteoclastogenesis and profoundly inhibit bone formation $(3,4)$. While an increased receptor activator of NF-кB ligand (RANKL)/osteoprotegerin (OPG) ratio in osteoblastic cells promotes osteoclastogenesis, inhibition of osteoblast differentiation, reduced matrix production, increased osteoblast and osteocyte apoptosis and increased autophagy further seem to contribute to GIO $(5,6,7,8)$.

To gain further insight into the underlying mechanisms of GC-induced suppression of bone formation, we focused on the Wnt signaling pathway as it plays an important role during osteoblast development. In our previous work, we showed that the Wnt inhibitor Dickkopf-1 (Dkk-1) is increased by GCs in mice and osteoblast cell cultures. Moreover, this regulation is dependent on the GC receptor (GR) (9). In vivo studies indicate that suppression of Dkk-1 using RNA interference or knockout of Dkk-1 in osteoblasts and osteocytes prevents GC-induced bone loss in mice. Thus, the GC-mediated induction of Dkk-1 in osteogenic cells is a critical pathogenic mechanism of GIO (S Thiele, U Baschant, LC Hofbauer, M Rauner, unpublished observations; 10). Recently, studies have proposed a contribution of another Wnt inhibitor, sclerostin, to the pathophysiology of GIO. However, data are contradictory $(11,12,13,14)$. Sclerostin is expressed mostly by osteocytes, making it a favorable candidate to specifically target Wnt signaling in the bone compartment $(15,16,17)$. However, SOST expression has also been reported in other cell types, for example, hypertrophic chondrocytes and cementocytes (18). Sclerostin-deficient mice display increased bone formation, bone mass and strength, underlining its negative regulation of bone homeostasis (19). Blocking sclerostin using specific antibodies has already been shown to restore bone mass in conditions of estrogen deficiency (20), hyperthyroidism (21), aging (22), disuse (23) and colitis (24) in rodents. Therefore, the aim of this study was to comprehensively investigate the regulation of sclerostin by GCs in vivo and in vitro in mice and in humans to evaluate its potential as therapeutic target to treat GIO.

\section{Materials and methods}

\section{Induction of glucocorticoid-induced bone loss in mice}

Male C57BL/6 JRj and DBA/1JRj mice were purchased from Janvier (Saint Berthevin Cedex, France) and housed under institutional guidelines. All mice $(n=10)$ were fed a standard diet with water ad libitum and were kept in a 12:12 h light:darkness cycle at room temperature in filter top cages with cardboard houses as enrichment. The local animal care committee (Landesdirektion Sachsen) approved all animal procedures. To induce GC-induced bone loss (long-term approach), 6-month-old male C57BL/6 mice were implanted with 60-day slow-release pellets (Innovative Research of America, Sarasota, FL, USA) containing either vehicle or prednisolone (PRED; $7.5 \mathrm{mg}$ ) for 4 weeks. Mice were randomly assigned to the groups. For short-term GC treatment, 18-week-old male DBA/1 mice received either PBS or dexamethasone (DEX; $100 \mu \mathrm{g} / \mathrm{mouse}$ ) intraperitoneally, every second day for 10 days. After the respective treatment period, mice were killed to examine the effects on the skeleton.

In addition, a mouse model for Cushing's syndrome due to an N-ethyl-N-nitrosourea (ENU) induced mutation at $-120 \mathrm{bp}$ of the promoter region of the corticotropin releasing hormone gene $\left(\mathrm{Crh}^{-120 /+}\right)$, that resulted in an increased luciferase reporter activity and is thus a gainof-function mutation, was used as an endogenous model for GC excess (25). Male $\mathrm{Crh}^{-120 /+}$ mice $(n=5)$ and their littermate controls used in this study are congenic on a C57BL/6J background and were housed in the Mary Lyon Centre at MRC Harwell. Mice were kept and studied in accordance with UK Home Office legislation and local ethical guidelines issued by the Medical Research Council (Responsibility in the Use of Animals for Medical Research, July 1993; home office license 30/2642). Mice were kept under controlled light (light 07:00-19:00 h, dark 19:00-07:00h), temperature $\left(21 \pm 2^{\circ} \mathrm{C}\right)$ and humidity $(55 \pm 10 \%)$ conditions. They had free access to water (9-13 ppm chlorine) and were fed ad libitum. After 12 weeks, mice were killed to collect the serum.

\section{Culture of human and murine bone marrow- derived osteoblasts}

Primary human bone marrow stromal cells (hMSC) were collected from healthy donors (aged 22-49 years, mixed gender) following Institutional Review Board approval by the Technische Universität Dresden and obtaining written informed consent. The study was approved by the Institutional Review Board of the Technische Universität Dresden. The cells were cultured in DMEM (Thermo Fisher Scientific) with 10\% FCS (Biochrom, Berlin, Germany) and 1\% penicillin/streptomycin (P/S; Thermo Fisher Scientific) and were used in passages 3-5 (26). To induce osteogenic differentiation, 70\% confluent cells were switched to basal medium supplemented with $100 \mu \mathrm{M}$ ascorbate phosphate, $5 \mathrm{mM}$ b-glycerol phosphate and $10 \mathrm{nM}$ DEX (all from Sigma-Aldrich) for 21 days. 
Before treatment, cells were switched to starving media overnight and then treated with DEX (Sigma-Aldrich) at concentrations as indicated in the appropriate figure for $48 \mathrm{~h}$ and $72 \mathrm{~h}$, respectively.

For the culture of primary murine BMSC, femora and tibiae from WT C57BL/6 mice were flushed and seeded at a density of $1 \times 10^{6}$ cells per $\mathrm{cm}^{2}$ in DMEM supplemented with $10 \%$ FCS and $1 \% \mathrm{P} / \mathrm{S}$. To induce osteogenic differentiation, $70 \%$ confluent cells were switched to basal medium supplemented with $100 \mu \mathrm{M}$ ascorbate phosphate and $10 \mathrm{mM}$ b-glycerol phosphate for 21 days. Before treatment, cells were switched to starving media overnight and then treated with $1 \mu \mathrm{M}$ DEX for $48 \mathrm{~h}$.

\section{Overexpression and knock-down experiments}

Overexpression of the GC receptor (GR) was induced in hMSCs using $1 \mu \mathrm{g}$ GR plasmid-DNA (pCMX-HAhGRalpha, kindly provided by Karolien DeBosscher, University of Gent, Belgium) and $3 \mu \mathrm{L}$ of the transfection reagent Fugene HP (Roche). The plasmid-DNA was diluted in $100 \mathrm{~mL}$ Opti-MEM (Gibco Life Technologies), and after 5 min of incubation at RT, Fugene HD was added and incubated for $20 \mathrm{~min}$ at RT. The transfection mixture was added drop-wise to $70 \%$ confluent cells seeded in $1 \mathrm{~mL}$ growth medium in a six-well plate and incubated for $48 \mathrm{~h}$.

GR knockdown was performed using DharmaFECT (Thermo Fisher Scientific) and GR siRNA (s6187; Ambion Life Technologies). Nontargeting siRNA (Ambion Life Technologies) was used as control. DharmaFECT (transfection reagent) and siRNA were incubated in $100 \mu \mathrm{L}$ FCS-free Opti-MEM for $20 \mathrm{~min}$ at RT. Transfection mixture was added to a final concentration of $50 \mathrm{nM}$ to hMSC with P/S-free medium containing 10\% FCS. Medium was changed after $6 \mathrm{~h}$ to stop the transfection.

\section{RNA isolation, RT, and real-time PCR}

RNA from human and murine BMSCs was isolated using Trifast (Peqlab, Erlangen, Germany) after washing twice with PBS. RNA isolation was performed according to the manufacturer's protocol. Using Superscript II (Invitrogen), 500ng RNA were reverse transcribed and subsequently used for SYBR green-based real-time PCR reactions according to a standard protocol (Applied Biosystems). Primer sequences were human (hu) betaactin ( $A C T B$ ) forward (f): CCAACCGCGAGAAGATGA, hu $A C T B$ reverse (r): CCAGAGGCGTACAGGGATAG, murine (mu) Actb f: GATCTGGCACCACACCTTCT, mu Actb r: GGGGTGTTGAAGGTCTCAAA, hu osteocalcin (bone gamma-carboxyglutamate protein (BGLAP)) f: tgagagccetcacactcctc, hu BGLAP r: acctttgctggactctgcac, mu Bglap f: GCGCTCTGTCTCTCTGACCT, mu Bglap r: ACCTTATTGCCCTCCTGCTT, hu nuclear receptor subfamily 3, group C, member 1 (glucocorticoid receptor; NR3C1) f: GGCAGCGGTTTTATCAACTG, hu NR3C1 r: CAGCTAACATCTCGGGGAAT, hu SOST f: CACAGCCTTCCGTGTAGTGG, hu SOST r: ATTTCCGTGGCATCATTCTTG, mu Sost f: CGgagAatgGaGgCAGAC, mu sost r: GTCAGGAAGCGGGTGTAGTG. PCR conditions were $50^{\circ} \mathrm{C}$ for $2 \mathrm{~min}$ and $95^{\circ} \mathrm{C}$ for $10 \mathrm{~min}$ followed by 40 cycles with $95^{\circ} \mathrm{C}$ for $15 \mathrm{~s}$ and $60^{\circ} \mathrm{C}$ for $1 \mathrm{~min}$. The melting curve was assessed using the following program: $95^{\circ} \mathrm{C}$ for $15 \mathrm{~s}, 60^{\circ} \mathrm{C}$ for $1 \mathrm{~min}$ and $95^{\circ} \mathrm{C}$ for $30 \mathrm{~s}$. The results were calculated applying the $\Delta \Delta$-CT method and are presented in $\mathrm{x}$-fold increase relative to beta-actin.

\section{Analysis of sclerostin and bone formation and resorption markers in the serum and supernatant}

Pro-collagen type 1 N-terminal peptide (P1NP; IDS Immunodiagnostic Systems GmbH, Frankfurt am Main, Germany) as well as sclerostin (ALPCO) were measured in the serum of mice using commercially available ELISAs. Sclerostin was measured in the cell culture supernatant of hMSC (Biomedica Medizinprodukte GmbH \& Co KG, Vienna, Austria).

P1NP, osteocalcin and carboxy-terminal telopeptide of type I collagen (CTX) in humans were measured in serum samples on the IDS-iSYS Multi-Discipline Automated Analyser (Immunodiagnostic Systems Limited, Frankfurt am Main, Germany). Sclerostin concentrations in humans were measured in serum samples using the Biomedica sclerostin assay (Biomedica Medizinprodukte $\mathrm{GmbH} \&$ Co KG).

\section{Study populations}

Serum samples from 101 patients with RA and 21 patients with polymyalgia rheumatica (PMR) were collected at the Division of Rheumatology at the Department of Medicine III at the Technische Universität Dresden. The median disease duration at the time point of blood collection was 4.76 years for RA and 1.31 years for PMR, respectively. RA was defined according to the 2010 ACR/EULAR and PMR according to the ACR/EULAR classification criteria. Characteristics of the patient cohorts are given in Tables 1 and 2. Forty of the RA patients received biologic diseasemodifying anti-rheumatic drugs (DMARDs) with or

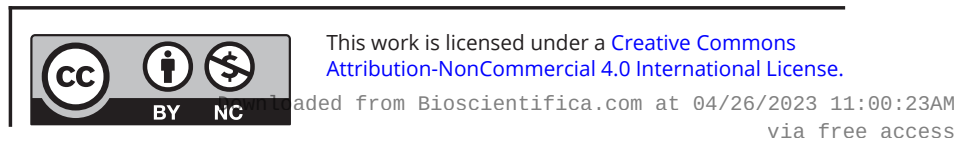


Table 1 Sclerostin in patients suffering from rheumatoid arthritis (RA) taking GC.

\begin{tabular}{l} 
Characteristics \\
\hline Disease \\
Sex, $n$ \\
Age, years \\
Current smokers, $n$ \\
BMI, kg/m ${ }^{2}$ \\
BMI categories, $n$ \\
Treatment \\
CDAl \\
CRP, mg/L \\
Auto-antibodies, $n$ \\
cGC dose (mg) \\
Actual GC dose at sampling (mg) \\
Patients taking GC at sampling, $n$ \\
Disease duration, years \\
Disease activity
\end{tabular}

\begin{tabular}{c}
\hline Controls \\
\hline 101 \\
32 \\
69 \\
$61.0(51.0-70.0)$ \\
34 \\
$27.4(24.9-30.0)$ \\
26 \\
49 \\
26
\end{tabular}

\begin{tabular}{|c|c|}
\hline Cases & P value $^{a}$ \\
\hline 101 & \\
\hline 32 & 1.00 \\
\hline 69 & \\
\hline $61.0(51.0-70.0)$ & 0.99 \\
\hline 34 & 1.00 \\
\hline $26.6(24.9-30.1)$ & 0.46 \\
\hline 26 & 1.00 \\
\hline 49 & \\
\hline 26 & \\
\hline 3 & \\
\hline 58 & \\
\hline 40 & \\
\hline $1.4(0.4-3.0)$ & \\
\hline $2.8(1.0-6.0)$ & \\
\hline 55 & \\
\hline 46 & \\
\hline $2500(1500-4775)$ & \\
\hline $0(0.0-5.0)$ & \\
\hline 49 & \\
\hline $4.76(1.91-8.86)$ & \\
\hline 75 & \\
\hline 20 & \\
\hline 6 & \\
\hline 12 & \\
\hline 33 & \\
\hline 18 & \\
\hline $42.2(33.4-55.4)$ & $<0.01$ \\
\hline $34.0(24.7-47.0)$ & 0.07 \\
\hline $10.6(7.2-13.9)$ & $<0.01$ \\
\hline $0.15(0.08-0.27)$ & $<0.01$ \\
\hline
\end{tabular}

For nominal variables $n(\%)$, for continuous variables median (1st-3rd quartile) are given. ${ }^{a}$ Chi-square test for nominal variables and Kruskal-Wallis test for continuous variables.

$\mathrm{BMI}$, body mass index; CDAl, clinical disease activity score; CGC, cumulative Glucocorticoid dose; CRP, C-reactive Protein; CTX, carboxy-terminal telopeptide of type I collagen; GC, Glucocorticoid; MTX, Methotrexate; P1NP, intact amino-terminal propeptide of type I procollagen; RA, rheumatoid arthritis.

without combination with conventional basis therapy (traditional DMARDs), while 58 RA patients received non-biologic (traditional) DMARDs. Three patients with RA received no conventional basis therapy. At the time of analysis, 75 RA patients were in remission, while 20 showed a low disease activity and six a high disease activity (Table 1). Analysis of DXA measurements showed that 12 of the RA patients had osteoporosis (T-score $<-2.5)$, while 33 displayed reduced bone density values (osteopenia, T-score -1 to -2.5 ) and 38 had normal bone density. For 18 of the patients we did not have data on bone mineral density.

Within the PMR group, two patients were treated with methotrexate (MTX) and four patients showed current disease activity at the time when the blood was collected (Table 2). Concerning the bone, we found that two of the patients displayed osteoporosis at the time of blood collection, while seven of the patients had osteopenia and six had normal T-scores. For four of the PMR patients we could not find DXA measurements. Age- ( \pm 3 years), sex-, smoking status- (current smoker vs non-smoker) and BMImatched (BMI-classes $<25 \mathrm{~kg} / \mathrm{m}^{2} ; \geq 25-29 \mathrm{~kg} / \mathrm{m}^{2} ; \geq 30 \mathrm{~kg} / \mathrm{m}^{2}$ ) controls $(n=122)$ were obtained from the Study of Health in Pomerania (SHIP)-1 cohort. Sampling methods and study protocols of the study have been reported previously (27). Subjects were not eligible as controls if they had a condition affecting bone metabolism or lack of information regarding these conditions (i.e. self-reported osteoporosis, RA, spondyloarthropathies, PMR, malignant disease, hyper- or hypothyroidism defined as thyroid stimulating hormone $<0.25$ or $>2.12 \mathrm{mU} / \mathrm{L}$, primary and secondary hyperparathyroidism defined as parathyroid hormone $>120 \mathrm{pg} / \mathrm{mL}$, hypogonadism in men defined as testosterone $<10.4 \mathrm{mmol} / \mathrm{L}$, chronic kidney disease defined as eGFR $<30 \mathrm{~mL} / \mathrm{min} / 1.73 \mathrm{~m}^{2}$, risky alcohol consumption defined as $\geq 30 \mathrm{~g} /$ day in men and $\geq 20 \mathrm{~g} /$ day https://ec.bioscientifica.com

https://doi.org/10.1530/EC-19-0104 (c) 2019 The authors Published by Bioscientifica Ltd
This work is licensed under a Creative Commons Attribution-NonCommercial 4.0 International License. ded from Bioscientifica.com at 04/26/2023 11:00:23AM 
Table 2 Sclerostin in patients suffering from polymyalgia rhematica (PMR) taking GC.

\begin{tabular}{|c|c|}
\hline \multicolumn{2}{|l|}{ Characteristics } \\
\hline Disease & PMR \\
\hline \multirow[t]{2}{*}{ Sex, $n$} & Male \\
\hline & Female \\
\hline \multicolumn{2}{|l|}{ Age, years } \\
\hline \multicolumn{2}{|l|}{ Current smokers, $n$} \\
\hline \multicolumn{2}{|l|}{$\mathrm{BMI}, \mathrm{kg} / \mathrm{m}^{2}$} \\
\hline \multirow[t]{3}{*}{ BMI categories, $n$} & $<25 \mathrm{~kg} / \mathrm{m}^{2}$ \\
\hline & $\geq 25-29 \mathrm{~kg} / \mathrm{m}^{2}$ \\
\hline & $\geq 30 \mathrm{~kg} / \mathrm{m}^{2}$ \\
\hline \multicolumn{2}{|l|}{ MTX, $n$} \\
\hline \multicolumn{2}{|l|}{$\mathrm{CRP}, \mathrm{mg} / \mathrm{L}$} \\
\hline \multicolumn{2}{|c|}{ cGC dose, mg } \\
\hline \multicolumn{2}{|c|}{ Actual GC dose at sampling, mg } \\
\hline \multicolumn{2}{|c|}{ Patients taking GC at sampling, $n$} \\
\hline \multicolumn{2}{|c|}{ Disease duration, years } \\
\hline \multirow[t]{3}{*}{ Bone status, $n$} & Osteoporosis (T-score <-2.5) \\
\hline & Osteopenia (T-score -1.0 to -2.5 ) \\
\hline & Not reported \\
\hline \multicolumn{2}{|l|}{ Sclerostin, pmol/L } \\
\hline \multicolumn{2}{|l|}{ PINP, ng/mL } \\
\hline \multicolumn{2}{|l|}{ Osteocalcin, ng/mL } \\
\hline CTX, ng/mL & \\
\hline
\end{tabular}

\begin{tabular}{c}
\hline Controls \\
\hline 21 \\
11 \\
10 \\
$74.0(72.0-76.0)$ \\
0 \\
$27.5(24.4-28.6)$ \\
6 \\
12 \\
3
\end{tabular}

\begin{tabular}{ccc}
\hline Cases & & P value $^{\mathbf{a}}$ \\
\cline { 1 - 1 } 21 & & \\
11 & & 1.00 \\
10 & & 0.99 \\
$73.0(72.0-75.0)$ & & 1.00 \\
0 & & 0.95 \\
$28.1(24.8-29.3)$ & & 1.00 \\
6 & & \\
12 & \\
3 & \\
2 &
\end{tabular}

CRP, mg/L

$1.31(0.42-4.22)$

2

7

$70.6(59.8-85.9)$

$31.2(21.8-61.2)$

$16.3(10.1-26.7)$

$51.9(40.0-59.2)$

For nominal variables $n(\%)$, for continuous variables median (1st-3rd quartile) are given. ${ }^{a}$ Chi-square test for nominal variables and Kruskal-Wallis test for continuous variables.

BMI, body mass index; CDAl, clinical disease activity score; CGC, cumulative Glucocorticoid dose; CRP, C-reactive Protein; CTX, carboxy-terminal telopeptide of type I collagen; GC, Glucocorticoid; MTX, Methotrexate; P1NP, intact amino-terminal propeptide of type I procollagen; PMR, polymyalgia rheumatica.

in women, acute inflammation defined as serum highsensitivity C-reactive protein concentration $>10 \mathrm{mg} / \mathrm{L}$ or pregnancy or were taking medications affecting bone metabolism (glucocorticoids, heparin, calcineurin inhibitors, anti-epileptic medication, bisphosphonates, parathyroid hormone, calcium, vitamin D preparations, selective estrogen receptor modulators).

The investigations in SHIP-1 as well as the investigation of the RA and PMR patients were carried out in accordance with the Declaration of Helsinki. Written informed consent was collected from all participants. The study methods were approved by the Institutional Review Board of the University of Greifswald and the Technische Universität Dresden, respectively.

\section{Statistical analysis}

Results are presented as means \pm standard deviation (s.D.) or medians with 1st-3rd quartiles. All in vitro experiments were repeated at least three independent times. Statistical evaluations of two group comparisons were performed using a two-sided Student's t-test. One-way ANOVA was used for experiments with more than two groups. Group differences in human samples were tested with chi-squared or Kruskal-Wallis tests. Correlations were analyzed using the Spearman correlation coefficient. $P$ values $<0.05$ were considered statistically significant.

\section{Results}

\section{Serum sclerostin levels are increased by endogenous and exogenous GC exposure in mice}

To investigate the regulation of sclerostin in mice, we treated two different mouse strains with GCs. Effects on bone microstructure and bone histomorphometry were reported previously and showed a decrease of bone volume and bone formation parameters in the prednisolonetreated group of C57BL/6 mice (28). As expected, bone formation was suppressed in both GC-treated mouse strains as indicated by lower levels of the bone formation marker P1NP (Fig. 1A and B). Suppression of bone formation was already apparent after 10 days of treatment (Fig. 1B). Sclerostin serum concentrations were increased by $54 \%$ in $\mathrm{C} 57 \mathrm{BL} / 6$ mice $(P<0.05)$ and $52 \%$ in $\mathrm{DBA} / 1$ mice $(P<0.01)$, respectively, compared to their untreated controls (Fig. 1A and B). To determine whether sclerostin is also upregulated in states of endogenous hypercortisolism, we investigated serum levels of sclerostin in mice with a gain-of-function point mutation in the

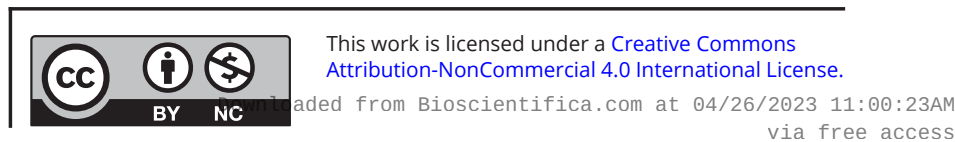




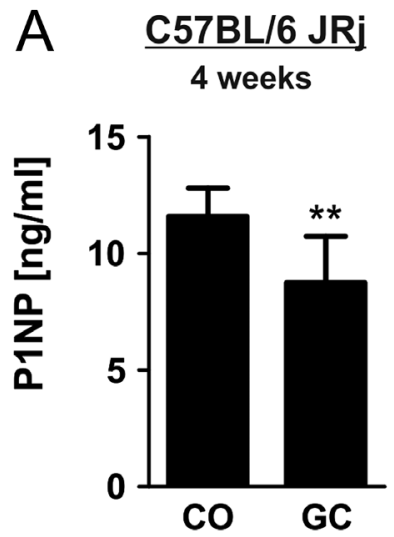

B DBA/1 JRj

10 days
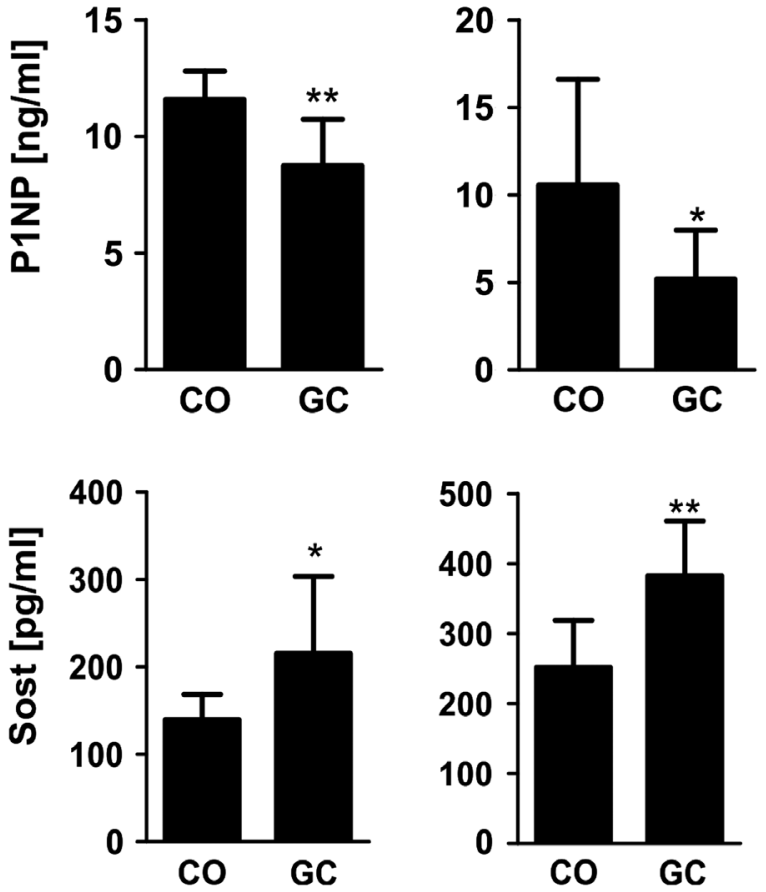

C $\mathrm{Crh}^{-120 /+}$ mice

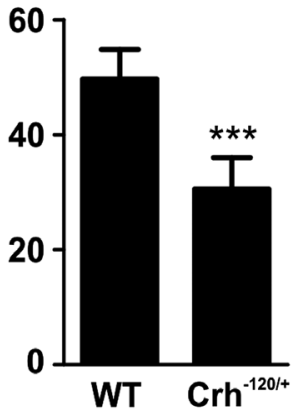

corticotropin-releasing hormone, leading to excessive levels of corticosterone. These mice displayed typical features of Cushing's syndrome including obesity, thin skin, muscle wasting and bone loss. Inhibited bone formation was verified in this model, detecting low P1NP serum levels in mice with endogenous hypercortisolism (Fig. 1C). In addition, serum levels of sclerostin were increased by $26 \%(P<0.05)$ (Fig. 1C). Thus, these data suggest that treatment with synthetic GCs as well as endogenous GC exposure both increased systemic sclerostin levels in mice.

\section{Regulation of sclerostin after GC treatment ex vivo and in vitro}

After having established that GC treatment increases sclerostin systemically, we asked whether the induction of Sost is also seen ex vivo or in vitro in femoral tissue of treated mice. Therefore, we isolated RNA from femora of GC-treated C57BL/6 mice. However, Sost expression was not regulated consistently in four independent experiments (Fig. 2A, B, C and D). Despite using the same mouse strain (C57BL/6 mice), age, sex, GC dose and treatment duration, Sost was increased three-fold $(P<0.05)$ in the first experiment, whereas two other experiments displayed a trend towards reduced Sost expression (-18 and $-51 \%$, respectively) and in the last experiment,

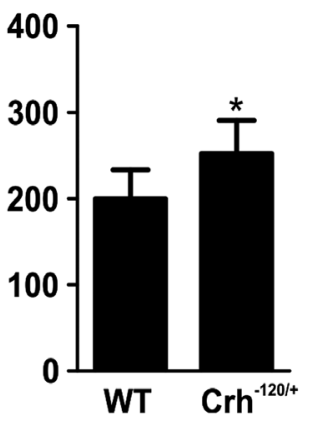

\begin{abstract}
Figure 1
Sclerostin (Sost) expression is increased by endogenous and exogenous glucocorticoid exposure in mice. Serum levels of procollagen type 1 amino-terminal propeptide (P1NP) and Sost were assessed in 24-week-old treated (vehicle (CO) or prednisolone (GC)) C57BL/6 JRi mice (A), DBA/1 JRi (B) mice and $\mathrm{Crh}^{-120 /+}$ mice with Cushing syndrome (C) using commercially available ELISAs. $n=5-10 ; * P<0.05 ; * \star P<0.01$; $\star \star \star P<0.001$ vs CO.
\end{abstract}

no difference was found. Pooled data of those experiments showed no difference in Sost expression (Fig. 2E). Similarly, no clear regulation of Sost was detected in mBMSC treated with DEX (Fig. 2F, G, H and I). While in our first experiment, mRNA expression of Sost tended to be increased 2- and 3-fold after treatment with DEX (0.1 and $1 \mu \mathrm{M}$ ) for $48 \mathrm{~h}$ (Fig. $2 \mathrm{~F}$ ), the second experiment showed a trend towards decreased Sost mRNA expression (Fig. 2G). Similarly, also the third and fourth experiment did not show a consistent regulation (Fig. $2 \mathrm{H}$ and $\mathrm{I}$ ) and again, pooling of normalized data displays a trend of increased Sost expression without significant differences (Fig. 2J). Sost expression was also not consistently regulated in the osteocytic cell lines Ocy454 and IDG-SW3 (data not shown). Taken together, despite the induction of serum levels of sclerostin, its expression is not consistently regulated in femoral bone tissue or in osteogenic cell cultures.

\section{Sclerostin expression is decreased after GC treatment in human bone marrow stromal cells}

To examine if sclerostin is regulated in human cells, we went on to investigate the influence of GCs on the expression of SOST in hMSC. Therefore, we treated hMSC with different doses of DEX for 24,48 and $72 \mathrm{~h}$. DEX treatment led to a significant dose- and 

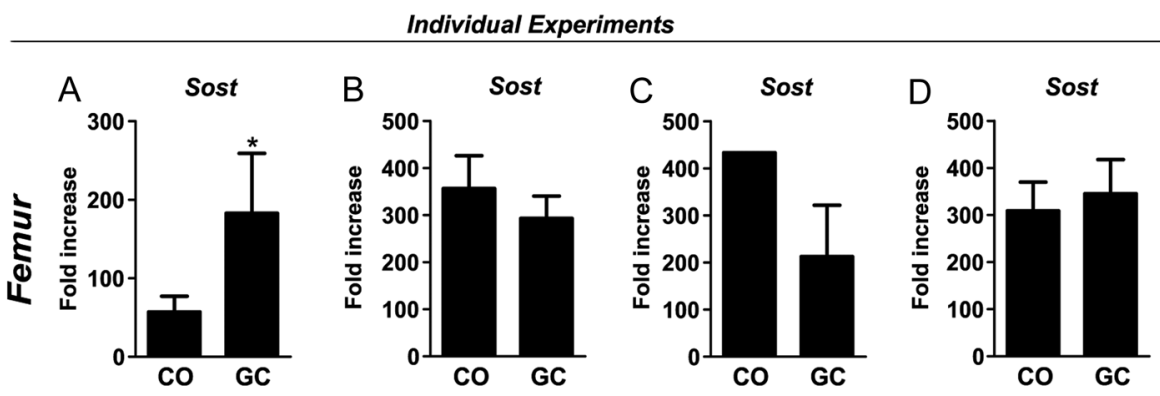

Pooled Experiments
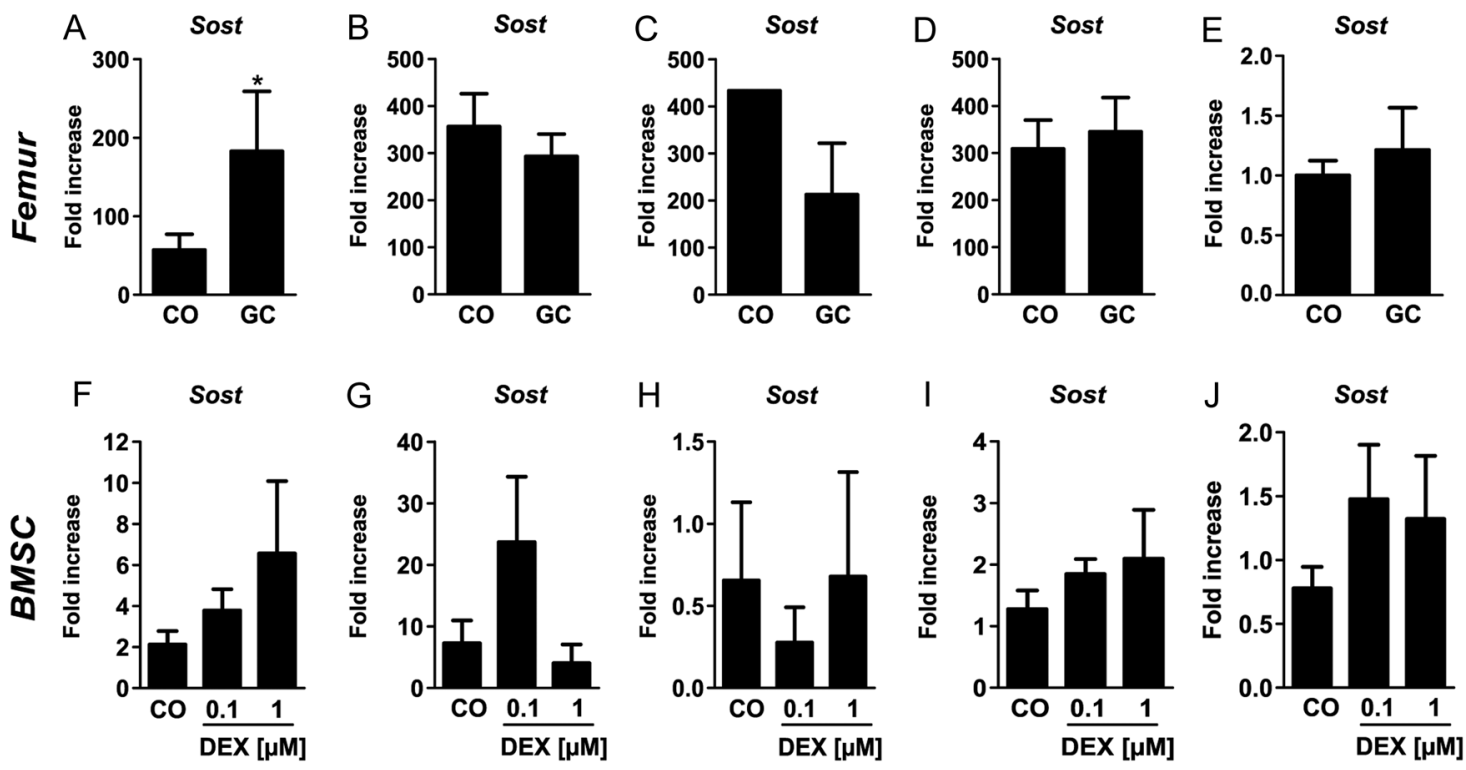

Figure 2

Sclerostin (Sost) expression is differentially regulated after glucocorticoid treatment ex vivo and in vitro. Real-time PCR analysis of Sost mRNA expression in murine femoral bone tissue of treated (vehicle (CO) or prednisolone (GC)) C57BL/6 JRi mice (A, B, C and D) and in murine bone marrow stromal cells (BMSC) treated with two different doses of dexamethasone (DEX; 0.1 and $1 \mu \mathrm{M} ; \mathrm{F}, \mathrm{G}, \mathrm{H}$ and I) for $48 \mathrm{~h}$. Figure $2 \mathrm{E}$ and J show normalized and pooled data of experiments A, B, C, D and F, G, H, I, respectively. $n=1-7 ;{ }^{*} P<0.05$ vs CO.

time-dependent decrease of SOST mRNA levels reaching a maximum suppression after $48 \mathrm{~h}$ at a concentration of $10 \mu \mathrm{M}$ (Fig. 3A and B). These results were confirmed at protein level (Fig. 3C and D). In addition, the osteoblastinhibiting properties of DEX were demonstrated by examining the expression of osteocalcin, which was also dose- and time-dependently decreased (bone gammacarboxyglutamate protein BGLAP/osteocalcin; Fig. 3E and F). As shown previously, these concentrations of DEX did not affect cell viability (26).

\section{Sclerostin expression depends on the presence of the GR}

We next set out to investigate whether the downregulation of SOST by GCs is GR dependent. To investigate the regulation of SOST by the GR, we overexpressed the GR in hMSC using pCMX-hGR, which resulted in a nine-fold increased mRNA expression of the GR (NR3C1; Fig. 4A). Furthermore, we found a three-fold higher mRNA expression of SOST in hMSC after transfection with pCMX-hGRa indicating an important role of the GR for SOST expression. DEX treatment reduced mRNA levels of SOST by 75\% in control cells and decreased SOST in GR-overexpressing hMSCs even further by $98 \%$ $(P<0.01$; Fig. 4B).
Furthermore, we knocked-down GR expression in hMSC using siRNA. GR (NR3C1) mRNA expression was downregulated by $83 \%(P<0.01)$ compared to controltreated cells (Fig. 4C). Interestingly, while DEX treatment decreased SOST mRNA expression by $87 \%(P<0.01)$, also GR knockdown itself reduced SOST expression, suggesting that basal SOST expression depends on the GR (-90\%; $P<0.01$; Fig. 4D).

\section{Low sclerostin serum concentrations in patients taking glucocorticoids}

To further define the role of sclerostin in a human setting, we analyzed 122 patients who had previously received GCs to treat their disease. Those patients had either RA or PMR and were compared to healthy individuals matched for age, sex, smoking status and BMI. PMR was specifically chosen as those patients initially receive high doses of GCs. Patient characteristics are shown in Tables 1 and 2. At the time point of sampling, about half of the RA patients currently received GC, while all but one PMR patient were on GC treatment (Tables 1 and 2). Serum levels of sclerostin were decreased by $40 \%(P<0.01)$ in RA patients taking GC and by $27 \%(P<0.01)$ in PMR patients taking GC compared to matched controls (Tables 1 and 2). This was accompanied by decreased bone formation, indicated by

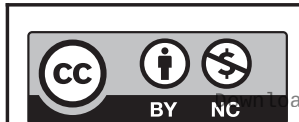

This work is licensed under a Creative Commons Attribution-NonCommercial 4.0 International License. ded from Bioscientifica.com at 04/26/2023 11:00:23AM 

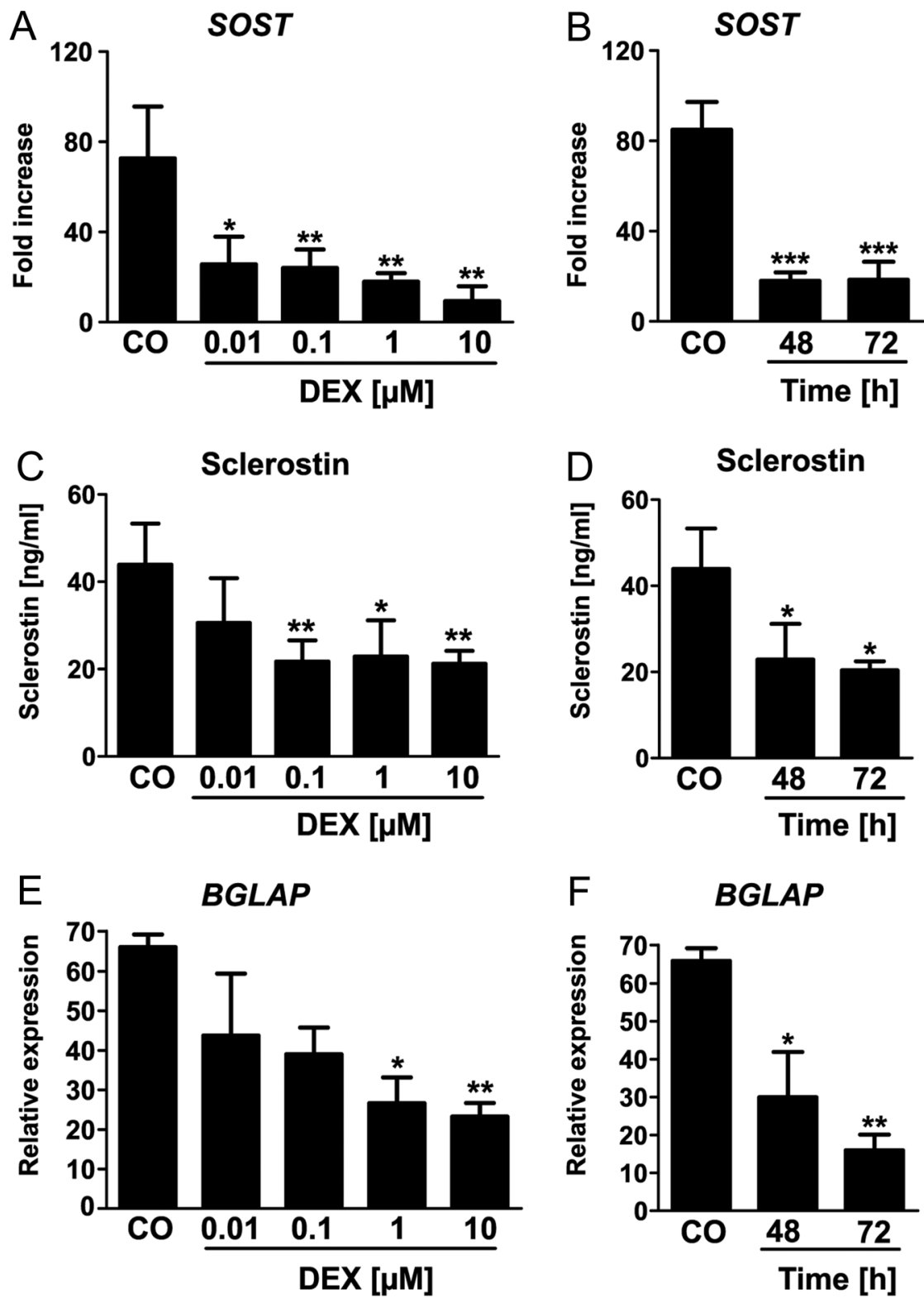

Figure 3

Sclerostin (SOST) expression is decreased after glucocorticoid treatment in human bone marrow stromal cells. Real-time PCR analysis of SOST mRNA expression in human mesenchymal stromal cells (HMSCs) treated with different doses of Dexamethasone (DEX; 0.01-10 $\mu \mathrm{M} ; \mathrm{A}$ ) for two different time points ( $48 \mathrm{~h}, 72 \mathrm{~h} ; \mathrm{B}) . n=3$; $\star P<0.05 ; * * P<0.01 ; * * * P<0.001$ vs CO. SOST protein concentration was measured in the supernatants of the treated HMSCs using a commercially available ELISA (C and D). $n=4$; $\star P<0.05 ; * * P<0.01$ vs 0 . The mRNA expression of osteocalcin (BGLAP) was also determined by real-time $\mathrm{PCR}$ analysis (E and F). $n=2-3$; ${ }^{*} P<0.05$; $* \star P<0.01$ vs CO.

decreased levels of osteocalcin, as well as a decrease in the bone resorption marker CTX in both cohorts, indicating reduced bone remodeling in GC-treated patients (Tables 1 and 2). Bone turnover markers in PMR patients were not affected as much as in patients with RA (Tables 1 and 2). Thus, these results suggest that the intake of GCs leads to decreased sclerostin serum levels.

\section{Discussion}

Osteoporosis is one of the most common and serious side effects of GC treatment as up to 50\% of GC-treated patients experience osteoporotic fractures $(3,20)$. Previous studies have shown that the suppression of Wnt signaling may be a key mechanism for the development of GIO. Here, we investigated the regulation of sclerostin, an important inhibitor of Wnt signaling, in mice and humans exposed to high levels of GCs. Our data showed that sclerostin is increased in the serum of mice with high endogenous or exogenous GC levels. However, its expression is not clearly regulated in bone tissue or murine BMSCs treated with GCs. In contrast, sclerostin levels are suppressed in human MSCs stimulated with GCs and in RA and PMR patients requiring GC therapy.

Contradictory results are found when searching for the regulation of sclerostin by GCs in the literature. A previous study had shown that mice implanted with https://ec.bioscientifica.com

https://doi.org/10.1530/EC-19-0104

(c) 2019 The authors Published by Bioscientifica Ltd
This work is licensed under a Creative Commons Attribution-NonCommercial 4.0 International License. ded from Bioscientifica.com at 04/26/2023 11:00:23AM 

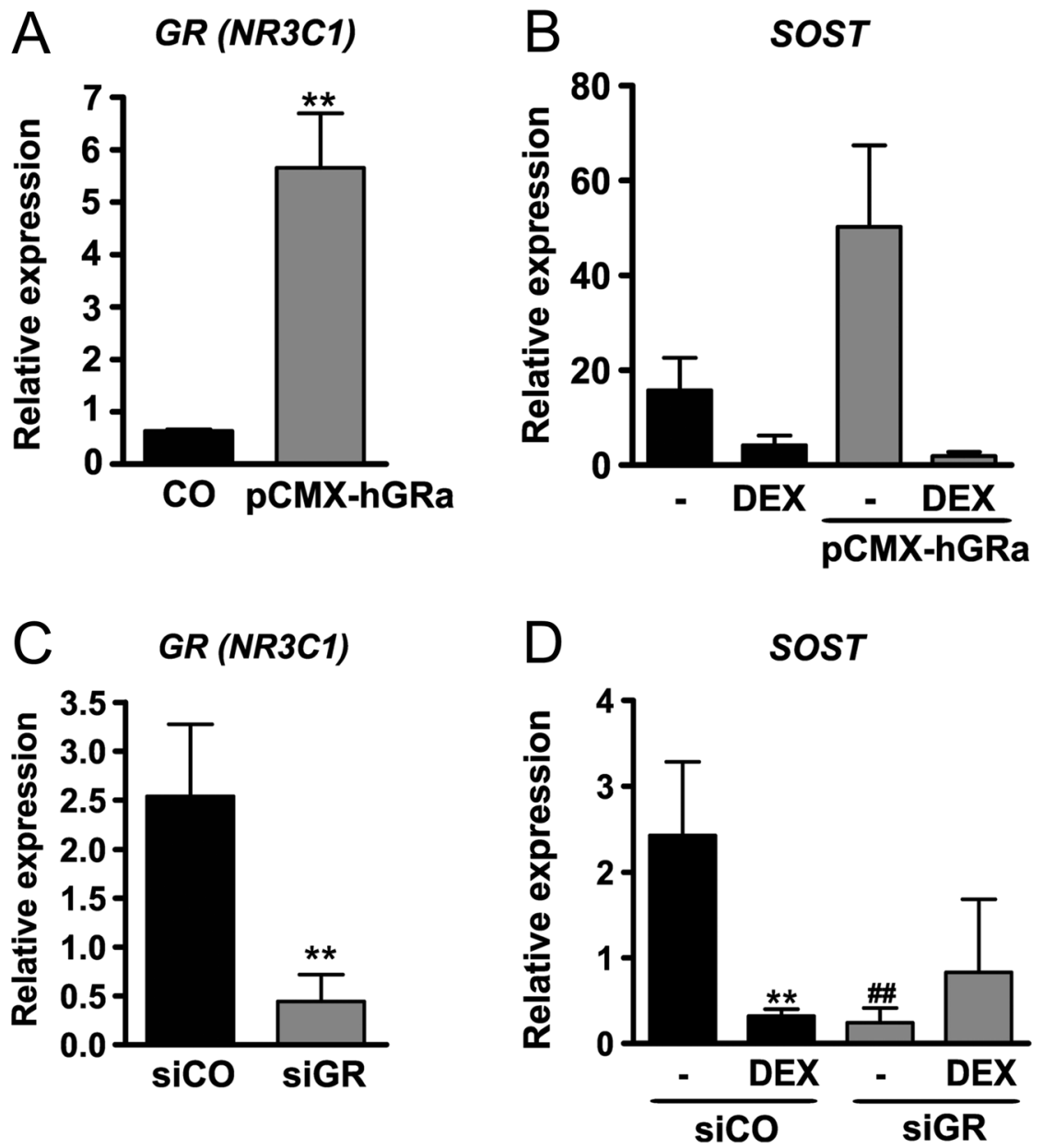
Figure 4
Sclerostin (SOST) expression depends on the presence of the glucocorticoid receptor (GR). The GR was overexpressed in human mesenchymal stromal cells (HMSCs) using pCMX-HA-hGRalpha and then left untreated or treated with dexamethasone (DEX; 0.1 and $1 \mu \mathrm{M}$ ) for $48 \mathrm{~h}$. The GR was knocked-down in HMSCs using siRNA and then left untreated or treated with DEX $(0.1 \mu \mathrm{M})$ for $48 \mathrm{~h}$. SOST (B, D) and NR3C1 (GR; A, C) gene expression levels were determined using qPCR. $n=4$; $* P<0.05 ; * \star P<0.01 ; * \star \star P<0.001$ vs CO; $\# P<0.01$ vs siCO

prednisolone pellets displayed increased serum sclerostin levels after 42 days. However, after 28 days no significant difference was found. Furthermore, Sost expression was transiently increased in calvarial osteoblasts after 12-h treatment with DEX, but not after 6 or $24 \mathrm{~h}$ (11). Also, increased Sost expression in the skeleton was found after 4 weeks of GC treatment in C57BL/6 mice (12). In contrast, skeletal Sost expression was not different after GC treatment of Swiss Webster mice (13) or SpragueDawley rats (14). Even though our study showed increased serum levels of sclerostin in three different models of high GC levels, skeletal expression was not different and also treating various osteogenic cells with GC did not regulate Sost expression. This raises the question if other cells than osteogenic cells may contribute to increased systemic levels of sclerostin after GC treatment in mice. In fact, also vascular smooth muscle cells (29) or periodontal ligament cells (30) have been shown to express Sost, albeit at lower levels as osteocytes. While different dosages, time intervals and mouse strains may account for some of the differences in results, overall, sclerostin does not seem to be consistently regulated by GCs in mice.

Despite the lack of clear regulation of sclerostin by GCs in mice, studies have investigated the potential of sclerostin-neutralizing antibodies for the treatment of GC-induced bone loss. A recent study demonstrated that mice lacking Sost are protected from GC-induced bone loss. Surprisingly, this was not mediated by rescuing the GC-induced decrease in bone formation, but via its anti-catabolic activity (12). Furthermore, treatment with sclerostin-neutralizing antibodies increased bone mass and strength in mouse models of GIO $(31,32)$. However, it should be noted that, even though animals treated with sclerostin antibodies displayed an overall higher bone volume, they lost even more bone after GC treatment than control animals suggesting that sclerostin does not play a major pathogenic role in GIO (32).

In contrast to our mouse studies, the regulation of sclerostin appeared more consistent in the human system as sclerostin was decreased after GC treatment in human bone marrow stromal cells. This regulation is
This work is licensed under a Creative Commons Attribution-NonCommercial 4.0 International License. ded from Bioscientifica.com at 04/26/2023 11:00:23AM 
most likely dependent on classical GR signaling as hMSCs treated with siGR and DEX did not show reduced SOST expression. In line with this, the SOST promoter contains several GC response elements, making it amenable to GC actions (11).

After showing that GC treatment decreased sclerostin expression in human cells we went on to investigate its concentration in sera of patients taking GCs. Sclerostin was markedly decreased in both cohorts of patients receiving GC therapy. Two other larger studies with 80 and 91 patients, respectively, showed decreased serum sclerostin concentrations after GC treatment of patients with chronic inflammatory diseases $(33,34)$. In addition, sclerostin was decreased after $96 \mathrm{~h}$ of GC treatment as compared to before GC treatment (35). Only one study reported increased levels of sclerostin after 1-year GC therapy $(>7.5 \mathrm{mg} /$ day $)$, although the increase was rather small (36). Of note, this is the only study that investigated patients with hematological disorders $(n=25)$ (36), indicating that the underlying diseases may also contribute to alterations in serum sclerostin levels. A differential regulation of sclerostin has also been reported in patients with hypercortisolism. While one study described lower levels of sclerostin in patients with endogenous hypercortisolism compared to healthy controls (37), another study found higher sclerostin levels $(38,39)$. However, diverse approaches for example different time points for taking the blood samples or collection of non-fasting versus fasting blood samples as well as the study populations themselves or the method used to determine the sclerostin level in the blood was different in the studies and may account for the differences in the results (37). Interestingly, not only bone formation parameters were low in our patient cohorts, but also bone resorption. As almost all patients received additional treatments during the time of blood sampling, these may have resulted in reduced inflammation but also reduced bone turnover.

Our study has potential limitations. First, different mouse strains were investigated albeit studies have shown that different mouse strains react distinctly to GC treatment in terms of bone loss $(9,40)$. Nonetheless, all mouse strains in this study showed suppressed bone formation parameters upon GC treatment, suggesting a robust and uniform mechanism of GC-mediated suppression of bone formation. Second, even though our patient cohorts were homogenous in terms of underlying disease, two-thirds of the RA patients were treated with DMARDs and half of the RA patients did not receive GC treatment at the time of sampling. However, in the PMR cohort, only two patients had an additional treatment with MTX, and all but one received GC at the time of blood analysis, suggesting that the observed effects on sclerostin levels should stem from the GC treatment. Moreover, it is not possible to perfectly distinguish between the effects of disease activity vs GC on sclerostin levels, and we could not correlate serum sclerostin levels with bone mineral density, as this parameter was not available for all patients. Nonetheless, suppression of bone formation appears to be a more sensitive marker for reflecting the negative effects of GC on bone.

Taken together this study shows that sclerostin is differentially regulated by GCs in mice and humans. While sclerostin serum levels are increased after GC administration in mice, its mRNA expression in murine BMSCs is not regulated. In contrast, sclerostin is decreased in human MSCs stimulated with GCs as well as in patients taking GCs suggesting that GC-induced bone loss is not primarily driven via sclerostin.

\section{Declaration of interest}

$\mathrm{M} \mathrm{R}$ is a senior editor for Endocrine Connections. She was not involved in the editorial or peer review process for this paper, on which she is listed as an author. The other authors have nothing to disclose.

\section{Funding}

This work was supported by the European Calcified Tissue Society, the MedDrive start-up grant from the TU Dresden to S T and grants from the Deutsche Forschungsgemeinschaft to ST, LCH, and M R. R V T is supported by Medical Research Council UK (grant numbers G9825289 and G1000467) and a Welcome Trust Investigator Award. M R is supported by the Supportthe-Best Initiative of the TUD funded through the Excellence initiative of the German Federal and State Governments.

\section{Author contribution statement}

S T, A H, L C H and M R contributed to the study conception and design. $\mathrm{S} T, \mathrm{M} \mathrm{W}, \mathrm{U} B, \mathrm{H}$ W, M N, R V T, M B, A H and M R collected data and performed data analysis. Data were interpreted by $S T, A H, \cup B, H W$, M W, M N, R V T, M B, L C H and M R. S T, and M R drafted the manuscript. All authors critically revised the content of the manuscript and approved its final version. M R takes responsibility for the integrity of the data analysis.

\section{Acknowledgements}

The authors would like to thank Liz Bentley and Roger Cox from MRC Harwell Institute, Mammalian Genetics Unit, Harwell Campus, Oxfordshire, UK, for providing serum samples of $\mathrm{Crh}^{-120 /+}$ mice.

\section{References}

1 Hofbauer LC \& Rauner M. Minireview: live and let die: molecular effects of glucocorticoids on bone cells. Molecular Endocrinology 2009 23 1525-1531. (https://doi.org/10.1210/me.2009-0069)

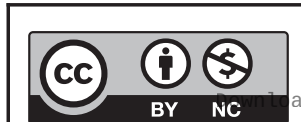

This work is licensed under a Creative Commons Attribution-NonCommercial 4.0 International License. ated from Bioscientifica com at 04/26/2023 11:00:23AM 
2 Van Staa TP, Leufkens HG, Abenhaim L, Zhang B \& Cooper C. Use of oral corticosteroids and risk of fractures. Journal of Bone and Mineral Research 200015 993-1000. (https://doi.org/10.1359/ jbmr.2000.15.6.993)

3 Eijken M, Hewison M, Cooper MS, de Jong FH, Chiba H, Stewart PM, Uitterlinden AG, Pols HAP \& van Leeuwen JPTM. 11betaHydroxysteroid dehydrogenase expression and glucocorticoid synthesis are directed by a molecular switch during osteoblast differentiation. Molecular Endocrinology 200519 621-631. (https:// doi.org/10.1210/me.2004-0212)

4 Sher LB, Woitge HW, Adams DJ, Gronowicz GA, Krozowski Z, Harrison JR \& Kream BE. Transgenic expression of 11betahydroxysteroid dehydrogenase type 2 in osteoblasts reveals an anabolic role for endogenous glucocorticoids in bone. Endocrinology 2004145 922-929. (https://doi.org/10.1210/en.2003-0655)

5 Weinstein RS, Jilka RL, Parfitt AM \& Manolagas SC. Inhibition of osteoblastogenesis and promotion of apoptosis of osteoblasts and osteocytes by glucocorticoids. Potential mechanisms of their deleterious effects on bone. Journal of Clinical Investigation $1998 \mathbf{1 0 2}$ 274-282. (https://doi.org/10.1172/JCI2799)

6 O'Brien CA, Jia D, Plotkin LI, Bellido T, Powers CC, Stewart SA, Manolagas SC \& Weinstein RS. Glucocorticoids act directly on osteoblasts and osteocytes to induce their apoptosis and reduce bone formation and strength. Endocrinology 2004145 1835-1841. (https:// doi.org/10.1210/en.2003-0990)

7 Kim HJ, Zhao H, Kitaura H, Bhattacharyya S, Brewer JA, Muglia LJ, Ross FP \& Teitelbaum SL. Glucocorticoids suppress bone formation via the osteoclast. Journal of Clinical Investigation $2006 \mathbf{1 1 6}$ 2152-2160. (https://doi.org/10.1172/JCI28084)

8 Hofbauer LC, Gori F, Riggs BL, Lacey DL, Dunstan CR, Spelsberg TC $\&$ Khosla S. Stimulation of osteoprotegerin ligand and inhibition of osteoprotegerin production by glucocorticoids in human osteoblastic lineage cells: potential paracrine mechanisms of glucocorticoidinduced osteoporosis. Endocrinology 1999140 4382-4389. (https:// doi.org/10.1210/endo.140.10.7034)

9 Thiele S, Ziegler N, Tsourdi E, De Bosscher K, Tuckermann JP, Hofbauer LC \& Rauner M. Selective glucocorticoid receptor modulation maintains bone mineral density in mice. Journal of Bone and Mineral Research 201227 2242-2250. (https://doi.org/10.1002/ jbmr.1688)

10 Wang FS, Ko JY, Yeh DW, Ke HC \& Wu HL. Modulation of Dickkopf-1 attenuates glucocorticoid induction of osteoblast apoptosis, adipocytic differentiation, and bone mass loss. Endocrinology 2008 149 1793-1801. (https://doi.org/10.1210/en.2007-0910)

11 Beier EE, Sheu TJ, Resseguie EA, Takahata M, Awad HA, CorySlechta DA \& Puzas JE. Sclerostin activity plays a key role in the negative effect of glucocorticoid signaling on osteoblast function in mice. Bone Research 20175 17013. (https://doi.org/10.1038/ boneres.2017.13)

12 Sato AY, Cregor M, Delgado-Calle J, Condon KW, Allen MR, Peacock M, Plotkin LI \& Bellido T. Protection from glucocorticoidinduced osteoporosis by anti-catabolic signaling in the absence of Sost/sclerostin. Journal of Bone and Mineral Research 201631 1791-1802. (https://doi.org/10.1002/jbmr.2869)

13 Yao W, Cheng Z, Busse C, Pham A, Nakamura MC \& Lane NE. Glucocorticoid excess in mice results in early activation of osteoclastogenesis and adipogenesis and prolonged suppression of osteogenesis: a longitudinal study of gene expression in bone tissue from glucocorticoid-treated mice. Arthritis and Rheumatism $2008 \mathbf{5 8}$ 1674-1686. (https://doi.org/10.1002/art.23454)

14 Ren H, Liang D, Jiang X, Tang J, Cui J, Wei Q, Zhang S, Yao Z, Shen G \& Lin S. Variance of spinal osteoporosis induced by dexamethasone and methylprednisolone and its associated mechanism. Steroids 2015 102 65-75. (https://doi.org/10.1016/j.steroids.2015.07.006)

15 Poole KES, van Bezooijen RL, Loveridge N, Hamersma H, Papapoulos SE, Löwik CW \& Reeve J. Sclerostin is a delayed secreted product of osteocytes that inhibits bone formation. FASEB Journal 200519 1842-1844. (https://doi.org/10.1096/fj.05-4221fje)

16 Winkler DG, Sutherland MK, Geoghegan JC, Yu C, Hayes T, Skonier JE, Shpektor D, Jonas M, Kovacevich BR, StaehlingHampton $\mathrm{K}$, et al. Osteocyte control of bone formation via sclerostin, a novel BMP antagonist. EMBO Journal 200322 6267-6276. (https:// doi.org/10.1093/emboj/cdg599)

17 van Bezooijen RL, Roelen BAJ, Visser A, van der Wee-Pals L, de Wilt E, Karperien M, Hamersma H, Papapoulos SE, ten Dijke P \& Löwik CW. Sclerostin is an osteocyte-expressed negative regulator of bone formation, but not a classical BMP antagonist. Journal of Experimental Medicine 2004199 805-814. (https://doi.org/10.1084/ jem.20031454)

18 Weivoda MM, Youssef SJ \& Oursler MJ. Sclerostin expression and functions beyond the osteocyte. Bone 201796 45-50. (https://doi. org/10.1016/j.bone.2016.11.024)

19 Li X, Ominsky MS, Niu QT, Sun N, Daugherty B, D'Agostin D, Kurahara C, Gao Y, Cao J, Gong J, et al. Targeted deletion of the sclerostin gene in mice results in increased bone formation and bone strength. Journal of Bone and Mineral Research 200823 860-869. (https://doi.org/10.1359/jbmr.080216)

20 Li X, Ominsky MS, Warmington KS, Morony S, Gong J, Cao J, Gao Y, Shalhoub V, Tipton B, Haldankar R, et al. Sclerostin antibody treatment increases bone formation, bone mass, and bone strength in a rat model of postmenopausal osteoporosis. Journal of Bone and Mineral Research 200924 578-588. (https://doi.org/10.1359/ jbmr.081206)

21 Tsourdi E, Lademann F, Ominsky MS, Rijntjes E, Köhrle J, Misof BM, Roschger P, Klaushofer K, Hofbauer LC \& Rauner M. Sclerostin blockade and zoledronic acid improve bone mass and strength in male mice with exogenous hyperthyroidism. Endocrinology 2017158 3765-3777. (https://doi.org/10.1210/en.2017-00247)

22 Li X, Warmington KS, Niu QT, Asuncion FJ, Barrero M, Grisanti M, Dwyer D, Stouch B, Thway TM, Stolina M, et al. Inhibition of sclerostin by monoclonal antibody increases bone formation, bone mass, and bone strength in aged male rats. Journal of Bone and Mineral Research 201025 2647-2656. (https://doi.org/10.1002/jbmr.182)

23 Tian X, Jee WSS, Li X, Paszty C \& Ke HZ. Sclerostin antibody increases bone mass by stimulating bone formation and inhibiting bone resorption in a hindlimb-immobilization rat model. Bone 2011 48 197-201. (https://doi.org/10.1016/j.bone.2010.09.009)

24 Eddleston A, Marenzana M, Moore AR, Stephens P, Muzylak M, Marshall D \& Robinson MK. A short treatment with an antibody to sclerostin can inhibit bone loss in an ongoing model of colitis. Journal of Bone and Mineral Research 200924 1662-1671. (https://doi. org/10.1359/jbmr.090403)

25 Bentley L, Esapa CT, Nesbit MA, Head RA, Evans H, Lath D, Scudamore CL, Hough TA, Podrini C, Hannan FM, et al. An N-ethyl$\mathrm{N}$-nitrosourea induced corticotropin-releasing hormone promoter mutation provides a mouse model for endogenous glucocorticoid excess. Endocrinology 2014155 908-922. (https://doi.org/10.1210/ en.2013-1247)

26 Rauner M, Goettsch C, Stein N, Thiele S, Bornhaeuser M, De Bosscher K, Haegeman G, Tuckermann J \& Hofbauer LC. Dissociation of osteogenic and immunological effects by the selective glucocorticoid receptor agonist, compound A, in human bone marrow stromal cells. Endocrinology 2011152 103-112. (https://doi. org/10.1210/en.2010-0456)

27 Volzke H, Alte D, Schmidt CO, Radke D, Lorbeer R, Friedrich N, Aumann N, Lau K, Piontek M, Born G, et al. Cohort profile: the study of health in Pomerania. International Journal of Epidemiology 201140 294-307. (https://doi.org/10.1093/ije/dyp394)

28 Colditz J, Thiele S, Baschant U, Garbe AI, Niehrs C, Hofbauer LC \& Rauner M. Osteogenic Dkk1 mediates glucocorticoid-induced, but not arthritis-induced bone loss. Journal of Bone and Mineral Research 2019 [epub]. (https://doi.org/10.1002/jbmr.3702) 
29 Leto G, D'Onofrio L, Lucantoni F, Zampetti S, Campagna G, Foffi C, Moretti C, Carlone A, Palermo A, Leopizzi M, et al. Sclerostin is expressed in the atherosclerotic plaques of patients who underwent carotid endarterectomy. Diabetes/Metabolism Research and Reviews 201935 e3069. (https://doi.org/10.1002/dmrr.3069)

30 Whitty C, Wardale RJ \& Henson FMD. The regulation of sclerostin by cathepsin $\mathrm{K}$ in periodontal ligament cells. Biochemical and Biophysical Research Communications 2018503 550-555. (https://doi. org/10.1016/j.bbrc.2018.05.160)

31 Achiou Z, Toumi H, Touvier J, Boudenot A, Uzbekov R, Ominsky MS, Pallu S \& Lespessailles E. Sclerostin antibody and interval treadmill training effects in a rodent model of glucocorticoid-induced osteopenia. Bone 201581 691-701. (https://doi.org/10.1016/j. bone.2015.09.010)

32 Yao W, Dai W, Jiang L, Lay EYA, Zhong Z, Ritchie RO, Li X, Ke H \& Lane NE. Sclerostin-antibody treatment of glucocorticoid-induced osteoporosis maintained bone mass and strength. Osteoporosis International 201627 283-294. (https://doi.org/10.1007/s00198-0153308-6)

33 Kawazoe M, Kaneko K, Shikano K, Kusunoki N, Nanki T \& Kawai S. Glucocorticoid therapy causes contradictory changes of serum Wnt signaling-related molecules in systemic autoimmune diseases. Clinical Rheumatology 201837 2169-2178. (https://doi.org/10.1007/ s10067-017-3689-3)

34 Braz NFT, Rocha NP, Vieira ÉLM, Gomez RS, Barbosa IG, Malheiro OB, Kakehasi AM \& Teixeira AL. Negative impact of high cumulative glucocorticoid dose on bone metabolism of patients with myasthenia gravis. Neurological Sciences 201738 1405-1413. (https:// doi.org/10.1007/s10072-017-2964-z)
35 Brabnikova Maresova K, Pavelka K \& Stepan JJ. Acute effects of glucocorticoids on serum markers of osteoclasts, osteoblasts, and osteocytes. Calcified Tissue International 201392 354-361. (https:// doi.org/10.1007/s00223-012-9684-4)

36 Gifre L, Ruiz-gaspà S, Monegal A, Nomdedeu B, Filella X, Guañabens N \& Peris P. Effect of glucocorticoid treatment on Wnt signalling antagonists (sclerostin and Dkk-1) and their relationship with bone turnover. Bone 201357 272-276. (https://doi. org/10.1016/j.bone.2013.08.016)

37 Van Lierop AH, Van Der Eerden AW, Hamdy NAT, Hermus AR, Den Heijer M \& Papapoulos SE. Circulating sclerostin levels are decreased in patients with endogenous hypercortisolism and increase after treatment. Journal of Clinical Endocrinology and Metabolism 201297 E1953-E1957. (https://doi.org/10.1210/jc.2012-2218)

38 Belaya ZE, Grebennikova TA, Melnichenko GA, Nikitin AG, Solodovnikov AG, Brovkina OI, Grigoriev AU, Rozhinskaya LY \& Dedov II. Effects of endogenous hypercortisolism on bone mRNA and microRNA expression in humans. Osteoporosis International 2018 29 211-221. (https://doi.org/10.1007/s00198-017-4241-7)

39 Belaya ZE, Rozhinskaya LY, Melnichenko GA, Solodovnikov AG, Dragunova NV, Iljin AV, Dzeranova LK \& Dedov II. Serum extracellular secreted antagonists of the canonical Wnt/b-catenin signaling pathway in patients with Cushing's syndrome. Osteoporosis International 201324 2191-2199. (https://doi.org/10.1007/s00198013-2268-y)

40 Ersek A, Santo AIE, Vattakuzhi Y, George S, Clark AR \& Horwood NJ. Strain dependent differences in glucocorticoid-induced bone loss between C57BL/6J and CD-1 mice. Scientific Reports $2016 \mathbf{6} 36513$. (https://doi.org/10.1038/srep36513)

Received in final form 4 June 2019

Accepted 11 June 2019

Accepted Preprint published online 11 June 2019 (c) 2019 The authors Published by Bioscientifica Ltd

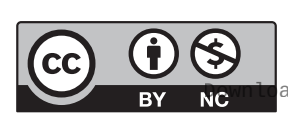

This work is licensed under a Creative Commons Attribution-NonCommercial 4.0 International License. ded from Bioscientifica.com at 04/26/2023 11:00:23AM 